\title{
Latissimus Dorsi Mini-Flap as a Volume Replacement Technique after Partial Mastectomy for Breast Cancer in the Upper and Central Breast Quadrants: A Single Center Experience
}

\author{
Waleed Elnahas, Ashraf Khater*, Mohamed Hamdy, Emadeldeen Hamed, Osama Eldamshety, \\ Mohamed Hegazy
}

Department of Surgical Oncology, Oncology Center, Faculty of Medicine, Mansoura University, Mansoura, Egypt

Email: ^dr.ashrafkhater@yahoo.com

How to cite this paper: Elnahas, W., Khater, A., Hamdy, M., Hamed, E., Eldamshety, O. and Hegazy, M. (2016) Latissimus Dorsi Mini-Flap as a Volume Replacement Technique after Partial Mastectomy for Breast Cancer in the Upper and Central Breast Quadrants: A Single Center Experience. Surgical Science, 7, 496-504. http://dx.doi.org/10.4236/ss.2016.711066

Received: August 4, 2016

Accepted: October 24, 2016

Published: October 27, 2016

Copyright $\odot 2016$ by authors and Scientific Research Publishing Inc. This work is licensed under the Creative Commons Attribution International License (CC BY 4.0).

http://creativecommons.org/licenses/by/4.0/ (c) (i) Open Access

\begin{abstract}
Background: The latissimus dorsi (LD) muscle flap plays an essential role in breast reconstruction after partial mastectomy for cancer because of its stability and versatility. We evaluated both oncologic and aesthetic outcomes in addition to the related complications of this flap as an adjunct to breast conserving surgery in the management of breast cancer patients. Methods: All patients underwent a one-stage procedure with immediate reconstruction through two-steps operation; wider local excision utilizing oncoplastic principles and mini flap harvest \& volume replacement. Results: The study included 34 cases with early breast cancer; 30 patients had partial breast resection and defect refilling by LD mini-flap, three patients underwent mastectomy and one patient underwent extended LDF. The mean defect volume was $\left(212.63 \mathrm{~cm}^{3} \pm 59.57\right) \mathrm{cm}^{3}$, while the mean flap volume was $\left(218.27 \mathrm{~cm}^{3} \pm 53.64 \mathrm{~cm}^{3}\right)$. Patient self-evaluation of the cosmetic outcome was excellent in $20 \%$, good in $60 \%$ and satisfactory in $20 \%$ of patients. Panel evaluation according to Harvard scale showed excellent in $36.7 \%$, good in $36.7 \%$, fair in $26.7 \%$ of patients. The median hospital stay was 4 days. The postoperative complications included wound gap in 4 patients (13.3\%), postoperative donor site seroma in 16 patients (53.3\%). No flap loss or necrosis, no affection on arm or shoulder mobility occurred. Lastly, no tumor recurrence till now. Conclusion: Latissimus dorsi mini-flap can achieve adequate cosmetic and oncologic outcomes with a low incidence of complications in patients with early stage (I/II) breast cancer and small to medium sized breasts.
\end{abstract}

\section{Keywords}

Oncoplastic, Breast Surgery, Latissimus Dorsi Mini-Flap, Conservative Surgery 


\section{Introduction}

Breast conservation is oncologically safe and can be properly achieved in about $70 \%$ of patients with early stage (I-II) breast cancer [1] [2] with an equal 5-year survival to mastectomy [3]. Asymmetry, nipple or skin retraction, and volume loss after breast conservation with primary closure frequently produce an unsatisfactory cosmetic outcome [4]. Recently, the combination of oncoplastic techniques with breast conservation results in better aesthetic and oncologic outcome with achieving wide safety margins [5]-[7]. The oncoplastic techniques include volume displacement or replacement procedures and sometimes include contra-lateral breast surgery. Among those oncoplastic procedures, local flaps, latissimus dorsi myocutaneous flap and reduction mammoplasty/masthopexy techniques. These are the most commonly employed procedures [8]. The latissimus dorsi (LD) flap is an important volume-replacement option due to its stability and versatility as an autologous flap [9]. LD flap could be used for total breast reconstruction after mastectomy in selective cases or to fill a large quadrantectomy defect [7]. In 2002, Rainsbury described LD mini flaps aiming to reconstruct the partial breast defects after central and upper quadrant resections. This oncoplastic approach allows extensive local excision during BCS without cosmetic penalties in a group of patients to avoid mastectomy [10].

The aim of this study was to evaluate the oncologic and aesthetic outcomes and the procedure-related complications of latissimus dorsi mini-flap as an adjunct to breast conserving surgery in management of partial mastectomy defects with or without incorporation of lateral thoracic skin island flap.

\section{Patient and Methods}

Through a prospective study that was carried out in the period from October 2014 to May 2016. This study included 34 cases with early stage (I \& II) breast cancer having small to medium breasts were managed with wide local excision. Preoperative preparation included so no-mammography, routine metastatic work up and routine laboratory assessment. Routine investigations were done also for to assess the histology, grade, biologic markers as ER, PR, Her2 neu, Ki67, operability, laterality, presence of contraindication of breast conserving techniques. After fulfilling all the criteria for partial breast resection that included; localized disease; as confirmed by preoperative mammography with no multi-centricity nor diffuse malignant appearing micro-calcifications, early stage (I or II) with no contraindications for radiotherapy, patients were enrolled into this study. Patients with advanced cases (stages III and VI) were excluded. Also exclusion was decided when complete tumor ablation could not be achieved (either due to multicenteric tumors, diffuse malignant appearing microcalcifications, or with contraindication of radiotherapy). When margin negativity was not possible after three attempts as guided by frozen section, mastectomies were done with exclusion from the study. Breast volume replacement with LD mini-flap was best suited for post-resection defects reaching up to $20 \%-30 \%$ of breast volume. Tumor location was an important factor in choosing this mini-flap. It was best tailored for filling the partial central and 
upper breast resection defects. In addition to the standard contraindications of breast conserving surgery, the following were considered as an exclusion criteria in our study; Previous division of the thoracodorsal pedicles, I psilateral thoracotomy with division of the latissimus dorsi muscle, Inability to obtain tumor free margins. After approval of the institutional review board, patients were consented for mastectomy if margin negativity was impossible and for this technique of reconstruction plus or minus lateral thoracic island flap if margin negativity was achieved.

\subsection{Operative Technique}

The whole procedure was carried out in supine position (not as originally described by Rains bury who carried out this technique while the patient was in lateral position). Placing patients in supine position throughout the whole operation is easier for both surgeon and the patient. After drawing of the tumor outline on the skin, a $2 \mathrm{~cm}$ circumferential line, marking the safety margin, was drawn around the periphery of the tumor. An S-shaped incision was subsequently drawn as starting from the apex of the axilla, through the lateral breast border towards the outer border of the infra-mammary fold (Figure 1). The LD anterior border was then marked. The following two steps were done:

1) Wide local excision utilizing the oncoplastic principles; the S-shaped incision was extended deeply into the subcutaneous fat and continued medially till the free outer border of pectoralis major muscle, then wide local excision of the tumor was performed and the margin status was confirmed "negative" by frozen section examination (Figure $1)$.

2) Mini flap harvest \& volume replacement: a superficial subcutaneous pocket was created in the premuscular plane starting from the anterior border of LD muscle towards the lumbosacral facia dorsally and the level of the costal margin inferiorly. The second deep muscular pocket was created deep to LD muscle in the same dimensions as

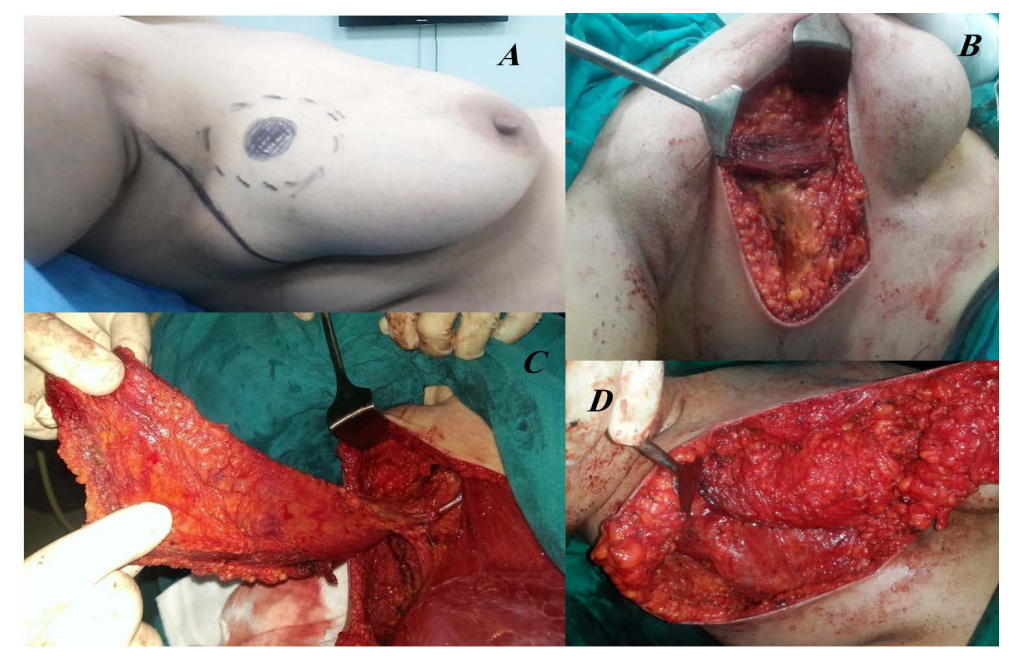

Figure 1. Steps of the mini-flap; A: design of the incision, B: excision defect, $\mathrm{C}$ : mini-flap retrieval through the same position, D: flap fixation. 
the superficial premuscular pocket. Then, the LD mini-flap was created by division of the LD muscle along the boundaries of the pockets. The muscle was firstly divided distally, and then posteriorly, passing up to the interval between LD and teres major muscles. After division, the LD mini-flap could be fully mobilized and to be delivered into the wound. After that, the tendon of the muscle was divided, leaving the flap attached only by the serratus anterior and thoracodorsal pedicles. This allowed maximum mobility during the flap repositioning into the defect. Moreover, the flap could be positioned more medially by division of the serratus anterior branches. Lastly the flap was folded and sutured to match the shape of the resection defect. The tendinous end of the flap was sutured to the outer free border of pectoralis major for protection of the thoraco-dorsal pedicle and prevention of flap retraction from the defect. The defect edges were sutured into the flap with few interrupted sutures to fold it into a shape that conforms to the defect. By folding over the tip of the flap, its most bulky part laid in the deepest part of the cavity (Figure 1).

\subsection{Follow up}

All patients were followed up for a mean of 10 months (range 2 - 16) for the possible complications and for the cosmetic outcome. Patients were examined regularly every two weeks after discharge. then the cosmetic outcome was assessed after 2, 6, 12 months postoperatively. During this period the oncologic outcome was assessed and there was no case of local recurrence or distant metastases.

\section{Results}

SPSS (Statistical Package for Social Sciences), version 15, was used for data analysis. Number and percent were used to represent the qualitative data while the mean \pm SD was used to represent the Quantitative data. P. value was estimated by Chi-Square test for comparison between the two groups and was considered to be statistically significant when less than $<0.05$.

LD mini-flap was planned to be the selected technique in 34 patients with proven breast cancer to refill the defect after partial breast resection. Patients and tumors criteria are described in Table 1 . Guided by intraoperative frozen section to assess the tumor margins status; a thirty patients $(88.2 \%)$ underwent mini-LDF (including 2 patients in whom safety margins were free after re-excision), 3 patients $(8.8 \%)$ underwent mastectomy; 1 patient (2.9\%) underwent extended LDF. The mean defect volume was $\left(212.63 \mathrm{~cm}^{3} \pm 59.57\right) \mathrm{cm}^{3}$ with a range between $(140-378) \mathrm{cm}^{3}$, while the mean flap volume was $\left(218.27 \mathrm{~cm}^{3} \pm 53.64 \mathrm{~cm}^{3}\right)$ with range between $(157-370) \mathrm{cm}^{3}$.

Post-operative cosmetic outcome was assessed by combination of two methods, patient self-evaluation (Table 2) and observer (panel) evaluation (Table 3 ) as following:

\subsection{Patient Self-Evaluation}

The patient evaluated symmetry of both breasts, breast shape, NAC symmetry, NAC placement, and the visible scars by a score of 5 to 1 (Figure 2). 
Table 1. Patients and tumors criteria.

\begin{tabular}{|c|c|}
\hline Parameters & Mean/range, number/percentage \\
\hline Age (Y) & $41.85(31-50)$ \\
\hline BMI & $29.06(22-40)$ \\
\hline \multicolumn{2}{|l|}{ Family history } \\
\hline 1 Member & $3(8.8 \%)$ \\
\hline 2 Members & 0 \\
\hline Three or more members & 0 \\
\hline \multicolumn{2}{|l|}{ Side } \\
\hline Rt. & $16(47.05 \%)$ \\
\hline $\mathrm{Lt}$ & $18(52.9 \%)$ \\
\hline \multicolumn{2}{|l|}{ Breast cup } \\
\hline A & $3(8.8 \%)$ \\
\hline B & $31(91.2 \%)$ \\
\hline \multicolumn{2}{|l|}{ Degree of ptosis } \\
\hline Grade I & $6(17.6 \%)$ \\
\hline Grade II & $28(82.3 \%)$ \\
\hline \multicolumn{2}{|l|}{ Pathological type } \\
\hline $\operatorname{IDC}(\mathrm{NOS})^{*}$ & $30(88.2 \%)$ \\
\hline Mucinous & $1(2.9 \%)$ \\
\hline Medullary & $1(2.9 \%)$ \\
\hline $\mathrm{ILC}^{* *}$ & $2(5.9 \%)$ \\
\hline \multicolumn{2}{|l|}{ Intra-ductal component } \\
\hline Low $(<25 \%)$ & $29(85.2 \%)$ \\
\hline High $(26 \%-49 \%)$ & $4(11.7 \%)$ \\
\hline Extensive (>50\%) & $1(2.9 \%)$ \\
\hline Tumor size $(\mathrm{cm})^{* \star *}$ & $2.42(1-3)$ \\
\hline \multicolumn{2}{|l|}{ Nodal involvement } \\
\hline Yes & $14(41.2 \%)$ \\
\hline No & $20(58.8 \%)$ \\
\hline \multicolumn{2}{|l|}{ Margins } \\
\hline Involvement & $6(17.6 \%)$ \\
\hline Persistent infiltrated margins & $3(8.8 \%)$ \\
\hline Distance $(\mathrm{mm})^{* * * *}$ & $21(13-34)$ \\
\hline
\end{tabular}

${ }^{\star} \mathrm{IDC}=$ infiltrating ductal carcinoma, NOS $=$ not otherwise specified, ${ }^{\star *} \mathrm{ILC}=$ infiltrating lobular carcinoma, ${ }^{* * *}$ tumor size was assessed in 32 patients as two patients in the study have disturbed breast cancer "Tx", ${ }^{* * *}$ assessed in 31 patients after exclusion of 3 patients with persistent infiltrated margins by frozen section.

Table 2. Patient self-assessment results.

\begin{tabular}{cccc}
\hline Cosmetic outcome & score & Number (30) & Percent $(100 \%)$ \\
\hline Satisfactory & 3 & 6 & $20 \%$ \\
Good & 4 & 18 & $60 \%$ \\
Excellent & 5 & 6 & $20 \%$ \\
\hline
\end{tabular}


Table 3. The overall cosmetic results (panel evaluation).

\begin{tabular}{ccc}
\hline Cosmetic outcome & Number of patients & percentage \\
\hline Excellent & 11 & $36.7 \%$ \\
Good & 11 & $36.7 \%$ \\
Fair & 8 & $26.7 \%$ \\
total & 30 & $100 \%$ \\
\hline
\end{tabular}

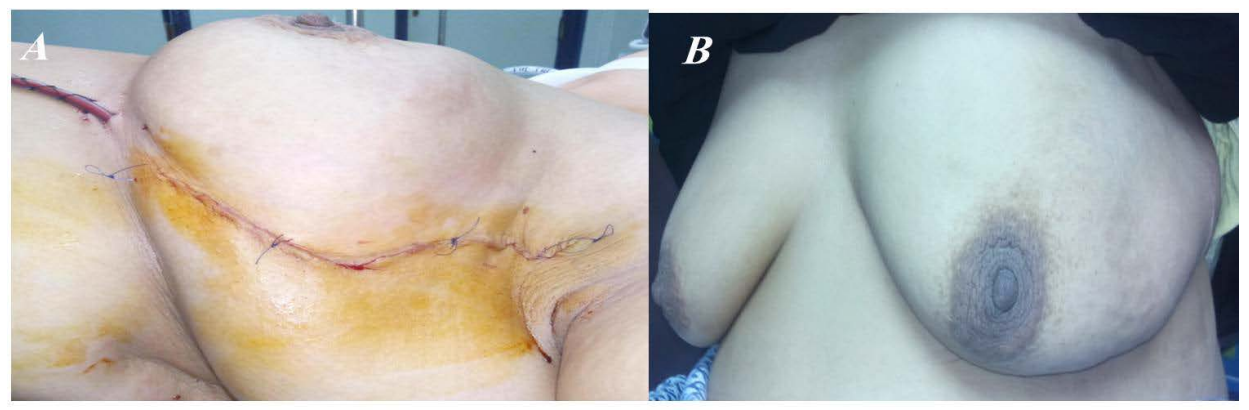

Figure 2. A: immediate postoperative view, B: three months later postoperative.

\subsection{Observer Evaluation (Panel Evaluation)}

The aesthetic results as judged by breast surgeons (not from the operating team) were assessed. The cosmetic outcome of the treated breast was evaluated in comparison with the untreated breast. This evaluation included seven items using the 4-point Likert scale based on the questionnaire described by Aaronson et al.: I: breast volume; II: breast shape; III: breast deformity; IV: NAC position; V: appearance of the breast scar; VI: skin changes; and VII: overall aethetic result [11].

The observed postoperative complications in this study were as following; wound gap in 4 patients (13.3\%) that was healed successfully with conservative treatment and postoperative donor site seroma in 16 patients (53.3\%) that required weekly aspiration with a median of 4 weeks till full resolution. No flap loss or necrosis was encountered. No affection for arm or shoulder mobility was observed. Lastly, no tumor recurrence occurred on the short term follow up. The median hospital stay was 4 days.

\section{Discussion}

Breast volume replacement with LD mini-flap is best tailored for filling the partial resection defects in small to medium breasts. Removal of $20 \%-30 \%$ of breast tissue could lead to poor aesthetic outcome. LD mini-flap could be the suitable choice for patients who wish to avoid mastectomy when $20 \%-30 \%$ of the breast volume has to be removed to achieve tumor-free margins. Also, LD mini-flap should be considered for those refusing contralateral symmetrizing surgery, or those who don't prefer the use of implants or expanders. Tumor location is an important factor in choosing LD mini-flap and is best tailored for reconstruction of central and upper quadrants resection defects. Latissimus dorsi mini flap was performed as initially described by Richard Rainsbury in 
2002. The procedure was best described as a two-step operation; wide local excision utilizing the oncoplastic principles and mini flap harvest \& volume replacement [10]. Olivotto et al. reported a poor aesthetic outcome of the breast when a volume of more than $70 \mathrm{~cm}^{3}$ of breast has to be excised [12]. In our study, although the resected specimens with a mean volume size of $212.63 \mathrm{~cm}^{3}$ could achieve a good loco-regional control, this led to a cosmetically unacceptable result without volume replacement procedure. These results were similar to other studies. Dixon et al. reported significantly larger weight of a median of $94 \mathrm{~g}$, (range $56-320 \mathrm{~g}$ ) of excised breast tissue when the LD mini-flaps were used [7]. Nano et al. reported a median weight of $130 \mathrm{~g}$ (range 75 - $395 \mathrm{~g}$ ) with LD mini-flap [13]. Cosmetically satisfactory results were achieved in (73.4\%) of cases using panel assessment and (80\%) by patients self-assessment. These results compares favorably with those reported by other series, taking into consideration that many of our patients were overweight. Hernanz et al. reported a satisfactory cosmoses in (65\%) of cases after a long follow-up period of 54 months [14]. Moreover, Naguib reported a 69\% satisfactory cosmetic outcome in a series of 29 patients, after a follow-up ranging from 3 to 36 months [15]. Being a single stage operation (at the time of breast resection and axillary dissection), as described by Raja et al, Rains bury and Paramanathan, and Noguchi et al., LD mini-flap is more time saving and hence a cost effective [16]-[18]. Postoperatively, no serious problems with wound sepsis or flap necrosis were met. Apffelstaedt reported recipient site sepsis in (1.2\%) and flap necrosis in $(8.4 \%)$ of his patients. These results could be explained by prior radio and chemotherapy given to his patients and the large flaps that he used. Their mean dimensions were (32 by $14 \mathrm{~cm}$ ) requiring donor site grafting in all his cases [19]. Donor site seroma was the only troublesome postoperative complication. We had (53.3\%) of our patients who required weekly aspiration by a mean of 4 weeks. Similar results in a study by Naguib who reported seroma in $(52 \%)$ of his patients that disappeared after a mean of five weeks of aspirations [15]. Throughout a regular follow-up visits, the presence of the LD flap did not limit the efficacy of clinical or radiological evaluation in any patient. Monticciolo et al. stated that the procedure caused no delay in starting adjuvant therapy in any of his cases and accordingly it did not compromise the patients' chances for cure [20]. The procedure proved to be easy and safe as evidenced by its relatively short duration (mean: 293 minutes), minimal blood loss (mean: $165 \mathrm{ml}$ ), with no need for blood transfusion and short hospital stay.

\section{Conclusion}

LD mini-flap is a feasible procedure and safe from the oncological sight. LD mini-flap can achieve an adequate cosmetic outcome when $20 \%-30 \%$ of the breast has to be resected leaving a large partial resection defect in small to medium sized breasts with early stage (I/II) breast cancer. The procedure has a low incidence of complications. Modification of the original mini-flap technique was done in our study. We carried out the whole procedure while the patients are in supine position, which is easier for the surgeons, better to the patients and less time consuming. 


\section{Acknowledgements}

Authors are thankful for Dr. Omar Hamdy and Dr. Mohamed Zohdy for their help throughout this study.

\section{References}

[1] Whelan, T., Levine, M., Gang, A., Sanders, K., Willed, A., Mirsky, D., et al. (1999) Mastectomy or Lumpectomy? Helping Women Make Informed Choices. Journal of Clinical Oncology, 17, 1727-1735.

[2] Fisher, B., Anderson, S., Bryant, J., Margolese, R., Deutsch, M., Fisher, E., et al. (2002) Twenty-Year Follow-Up of a Randomized Trial Comparing Total Mastectomy, Lumpectomy, and Lumpectomy plus Irradiation for the Treatment of Invasive Breast Cancer. New England Journal of Medicine, 347, 1233-1241. http://dx.doi.org/10.1056/NEJMoa022152

[3] Hamdi, M., Wolfli, J. and Van Landuyt, K. (2007) Partial Mastectomy Reconstruction. Clinics in Plastic Surgery, 34, 51-62. http://dx.doi.org/10.1016/j.cps.2006.11.007

[4] Asgeirsson, K., Rasheed, T., McCulley, S. and Macmillan, R. (2005) Oncological and Cosmetic Outcomes of Oncoplastic Breast Conserving Surgery. European Journal of Surgical Oncology (EJSO), 31, 817-823. http://dx.doi.org/10.1016/j.ejso.2005.05.010

[5] Munhoz, A.M., Montag, E. and Gemperli, R. (2013) Oncoplastic Breast Surgery: Indications, Techniques and Perspectives. Gland Surgery, 2, 143-157.

[6] Munhoz, A., Aldrighi, C. and Ferreira, M. (2007) Paradigms in Oncoplastic Breast Surgery: A Careful Assessment of the Oncological Need and Esthetic Objective. Breast Journal, 13, 326-327. http://dx.doi.org/10.1111/j.1524-4741.2007.00437.x

[7] Dixon, J., Venizelos, B. and Chan, P. (2002) Latissimus Dorsi Mini-Flap: A Technique for Extending Breast Conservation. The Breast, 11, 58-65. http://dx.doi.org/10.1054/brst.2001.0312

[8] Munhoz, A., Montag, E., Arruda, E., Pellarin, L., Filassi, J., Piato, J., et al. (2008) Assessment of Immediate Conservative Breast Surgery Reconstruction: A Classification System of Defects Revisited and an Algorithm for Selecting the Appropriate Technique. Plastic and Reconstructive Surgery, 121, 716-727. http://dx.doi.org/10.1097/01.prs.0000299295.74100.fa

[9] Zaha, H. and Onomura, M. (2013) Breast Conserving Surgery Using the Round Block Technique Combined with Partial Reconstruction Using the Latissimus Dorsi Flap. The Breast, 22, 98-99. http://dx.doi.org/10.1016/j.breast.2012.10.010

[10] Rainsbury, R. (2002) Breast-Sparing Reconstruction with Latissimus Dorsi Miniflaps. European Journal of Surgical Oncology (EJSO), 28, 891-895. http://dx.doi.org/10.1053/ejso.2002.1350

[11] Aaronson, N.K., Bartelink, H., van Dongen, J.A. and van Dam, F.S.A.M. (1988) Evaluation of Breast Conserving Therapy: Clinical, Methodological and Psychosocial Perspectives. European Journal of Surgical Oncology, 14, 133-140.

[12] Olivotto, I., Rose, M., Osteen, R., Love, S., Cady, B., Silver, B., et al. (1989) Late Cosmetic Outcome after Conservative Surgery and Radiotherapy: Analysis of Causes of Cosmetic Failure. International Journal of Radiation Oncology ${ }^{\star}$ Biology ${ }^{\star}$ Physics, 17, 747-753. http://dx.doi.org/10.1016/0360-3016(89)90061-8

[13] Nano, M., Gill, P., Kollias, J. and Bochner, M. (2004) Breast Volume Replacement Using the Latissimus Dorsi Miniflap. ANZ Journal of Surgery, 74, 98-104.

http://dx.doi.org/10.1046/j.1445-2197.2003.02917.x

[14] Hernanz, F., Regaño, S., Vega, A. and Gómez Fleitas, M. (2010) Reduction Mammaplasty: 
An Advantageous Option for Breast Conserving Surgery in Large-Breasted Patients. Surgical Oncology, 19, 95-102. http://dx.doi.org/10.1016/j.suronc.2009.08.001

[15] Naguib, S. (2006) Expanding the Role of Breast Conservation Surgery by Immediate Volume Replacement with the Latissimus Dorsi Flap. Journal of the Egyptian National Cancer Institute, 18, 216-226.

[16] Noguchi, M., Minami, M., Earashi, M., Taniya, T., Miyazaki, I., Nishijima, H., et al. (1995) Oncologic and Cosmetic Outcome in Patients with Breast Cancer Treated with Wide Excision, Transposition of Adipose Tissue with Latissimus Dorsi Muscle, and Axillary Dissection Followed by Radiotherapy. Breast Cancer Research and Treatment, 35, 163-171. http://dx.doi.org/10.1007/BF00668206

[17] Rainsbury, R. and Paramanathan, N. (1998) Recent Progress with Breast-Conserving Volume Replacement Using Latissimus Dorsi Miniflaps in UK Patients. Breast Cancer, 5, 139147. http://dx.doi.org/10.1007/BF02966686

[18] Raja, M., Straker, V. and Rainsbury, R. (1997) Extending the Role of Breast-Conserving Surgery by Immediate Volume Replacement. British Journal of Surgery, 84, 101-105. http://dx.doi.org/10.1002/bjs.1800840138

[19] Apffelstaedt, J. (2002) Indications and Complications of Latissimus Dorsi Myocutaneous Flaps in Oncologic Breast Surgery. World Journal of Surgery, 26, 1088-1093. http://dx.doi.org/10.1007/s00268-002-6277-9

[20] Monticciolo, D., Ross, D., Bostwick, J., Eaves, F. and Styblo, T. (1996) Autologous Breast Reconstruction with Endoscopic Latissimus Dorsi Musculosubcutaneous Flaps in Patients Choosing Breast-Conserving Therapy: Mammographic Appearance. American Journal of Roentgenology, 167, 385-389. http://dx.doi.org/10.2214/ajr.167.2.8686611

\section{Submit or recommend next manuscript to SCIRP and we will provide best service for you:}

Accepting pre-submission inquiries through Email, Facebook, LinkedIn, Twitter, etc.

A wide selection of journals (inclusive of 9 subjects, more than 200 journals)

Providing 24-hour high-quality service

User-friendly online submission system

Fair and swift peer-review system

Efficient typesetting and proofreading procedure

Display of the result of downloads and visits, as well as the number of cited articles

Maximum dissemination of your research work

Submit your manuscript at: http://papersubmission.scirp.org/

Or contact ss@scirp.org 